\title{
Construction of and attributional differences in nurses' perceptions of the initial experience of pediatric nursing practice
}

\author{
Mika IZUMI ${ }^{1}$ and Chieko FUJIWARA ${ }^{2}$
}

Objective : The objective was to evaluate registered nurses' perceptions of their initial experience in pediatric nursing practice.

Methods : The participants were 459 registered nurses with at least 2 years' experience of pediatric nursing. They completed anonymous questionnaires related to their perceptions of the initial experience of pediatric nursing, as well as their self-actualization as a nurse and professionalism. Valid replies $(n=226)$ were analyzed.

Results : Nurses' perceptions of their initial experience of pediatric nursing comprised 2 factors, "professional development as a pediatric nurse" and "capacity to work". Nurses who had an interest in children, had more than 6 years' pediatric nursing experience, worked in an outpatient setting or where all patients were children, and wished to continue developing their pediatric nursing experience scored highly on "professional development as a pediatric nurse". Nurses who worked in environments where they were dealing only with child patients and those who expressed a desire to gain pediatric nursing experience in the future scored highly on "capacity to work".

Conclusions : In the initial stage of employment in pediatric nursing, nurses perceive that their "professional development as a pediatric nurse" is heightened through accumulation of experience in pediatric nursing. Furthermore, it seems that positive engagement in shaping workplace systems to accumulate work experience raised "capacity to work" among pediatric nurses.

Key words : nurse, pediatric nursing, 2-5 years' experience, initial experience, construction of perceptions

\section{Introduction}

As registered nurses accumulate experience in pediatric nursing, they are able to acquire pediatric nursing knowledge and skills, and this helps sick children and their families feel secure in the care they receive. The recipients of pediatric nursing are children and their families, and registered nurses engaged in pediatric nursing must therefore have an understanding of the specific characteristics of children's growth and development. In identifying the specific features of pediatric nurses, Saito et al. (1996) described four factors of knowing a more experienced role model nurse, respecting children, facilitating development, and having an empathetic attitude to parents, and argued that the professionalism of pediatric nurses is heightened by these four linked factors. In a discussion on the

${ }^{1}$ Doctoral course, Department of Children and Woman's Health, Area of Nursing Science, Division of Health Sciences, Graduate School of Medicine, Osaka University, Osaka

${ }^{2}$ Department of Children and Woman's Health, Area of Nursing Science, Division of Health Sciences, Graduate School of Medicine, Osaka University, Osaka 
specialty of pediatric nursing as perceived by pediatric nurses, Nishida (2003) stated that the expertise of pediatric nursing lies in the cultivation of autonomy to nurture and support children, of whatever age, to keep going in their own way, and identified support for the family, support for motivation to fight the illness, and support for growth and development as the components of this cultivation of autonomy. Based on this previous research, it would seem that the specialty of pediatric nursing, with its focus on supporting the growth and development of the child patient in the process of helping the child and family to undergo treatment and positively engage in recovery, takes quite a different form than the specialty of adult nursing.

At the same time, because of medical reforms implemented by the government from 2001, hospital stays are being shortened, and a situation has arisen in pediatric departments whereby patients with chronic conditions are undergoing medical care at home with outpatient visits (Ode, 2007). Under these circumstances, nurses have only the short period of inpatient treatment to understand the condition and stage of development of the pediatric patient and provide care to the patient and the family. Hence, it is important for the nurse to accumulate pediatric nursing experience in order to engage in appropriate care for the child and family.

However, current employment and personnel management practices for registered nurses in Japan assume that new graduate registered nurses employed in medical institutions will be allocated to a department for approximately 3 years, where they become competent in the work through experience. They also assume that rotation of registered nurses who have 3 years' experience in the same department is effective (Taniguchi et al., 2001). These assumptions lead to nurses being subject to rotation ; after 3 years' practical experience in pediatric nursing following graduation, reg- istered nurses are placed in the position of having to choose whether to move to a different specialist area to gain practical experience, or to further their experience in pediatric nursing.

The point at which registered nurses make choices about how to gain experience as nursing professionals occurs 2-5 years after graduation (Donner and Wheeler, 2001), so this is the period in which these nurses start to think about how to shape their future experience. In this initial $2-5$ years, it can be assumed that registered nurses will have acquired and put into practice a certain amount of pediatric nursing knowledge and skills, but it is not clear how they actually perceive pediatric nursing practice during this period. Registered nurses employed as new graduates with $2-5$ years' experience are generally in their mid-twenties, a developmental stage of adulthood Levinson defines as early adulthood, which is a period in which individuals explore various aspects of social life in the creation of their own lifestyle as an adult (Levinson, 1978). Taking this to be the case, it is a period in which registered nurses are looking back on their experience so far and considering whether to continue their present work in the future.

In this context, the aim of the present study was to examine the construction of registered nurses' perceptions of their initial experience in pediatric nursing practice, and to identify differences in the construction of perceptions according to their years of experience of pediatric nursing, as well as their own individual and professional attributes. The types of perceptions of practice held by nurses with 2-5 years' experience of pediatric nursing were demonstrated, and differences in constructions resulting from acquisition of experience of pediatric nursing were considered. We identified differences among these constructions in terms of years of pediatric nursing experience and individ- 
ual and professional attributes. We also considered the issues of whether these constructions change with experience, what kind of individual and professional attributes of the nurse influence these constructions, and how perceptions developed through initial experience of pediatric nursing practice are linked to nurses' desire to continue in pediatric nursing.

In this study, registered nurses practicing pediatric nursing are referred to as pediatric nurses.

\section{Methods}

\section{Participants}

The participants were 459 registered nurses with at least 2 years' experience of pediatric nursing. They were working in 38 specialist pediatric hospitals or general hospitals with a pediatric department throughout Japan. The study was limited to those with more than 2 years' experience of pediatric nursing because, in the process of professional development as a nurse, registered nurses tend to make choices about their aims as a professional nurse after 2 to 5 years' experience (Donner and Wheeler, 2001). This suggests that nurses with less than 2 years' experience are still at the stage of aiming to acquire the specific techniques required for their allocated post, and that it is nurses with at least 2 years' experience who start thinking about whether they want to further their experience in pediatric nursing.

\section{Period of study}

October 2008 to January 2009

\section{Survey methods}

Requests for cooperation in the study, consisting of documents explaining the purposes and content of the study and ethical considerations, were mailed to 105 institutions. These institutions were a random sample from a total of 917 institutions identified nationwide in the Hospitals Directory (Ministry of Health, 2003) as specialist pediatric hospitals or general hospitals with pediatric departments. Hospitals also met the further requirement of having at least 150 beds (confirmed via hospital homepages). Consent to participate in the research was obtained from 38 institutions (consent rate $36.1 \%$ ), comprising 34 general hospitals and four children's hospitals. A request was made to nurse managers in these institutions to administer the survey to nurses with at least 2 years' experience who were not employed in managerial roles, and these nurse managers were provided with copies of the questionnaire, an explanation of the questionnaire, and return envelopes. The questionnaire was completed by participants on their own time and returned directly by participants by post.

\section{Survey content}

Based on the research framework shown in Figure 1 , the following questionnaire items were selected.

1) Attributes

(1) Individual factors : age, sex, family living arrangements, interest in children, desire to work in allocated post, desire to engage in pediatric nursing at the time of graduation, desire to gain further experience in pediatric nursing at present and in the future.

(2) Professional factors : basic nursing curriculum qualifications, number of years' experience as a nurse, type and features of current workplace, conditions and age of child patients in current post, number of beds, and number of pediatric beds if current post was on a ward.

2) Nine items related to perceptions of initial experience of pediatric nursing practice

Nine items related to nurses' perceptions of initial experience of pediatric nursing practice were 


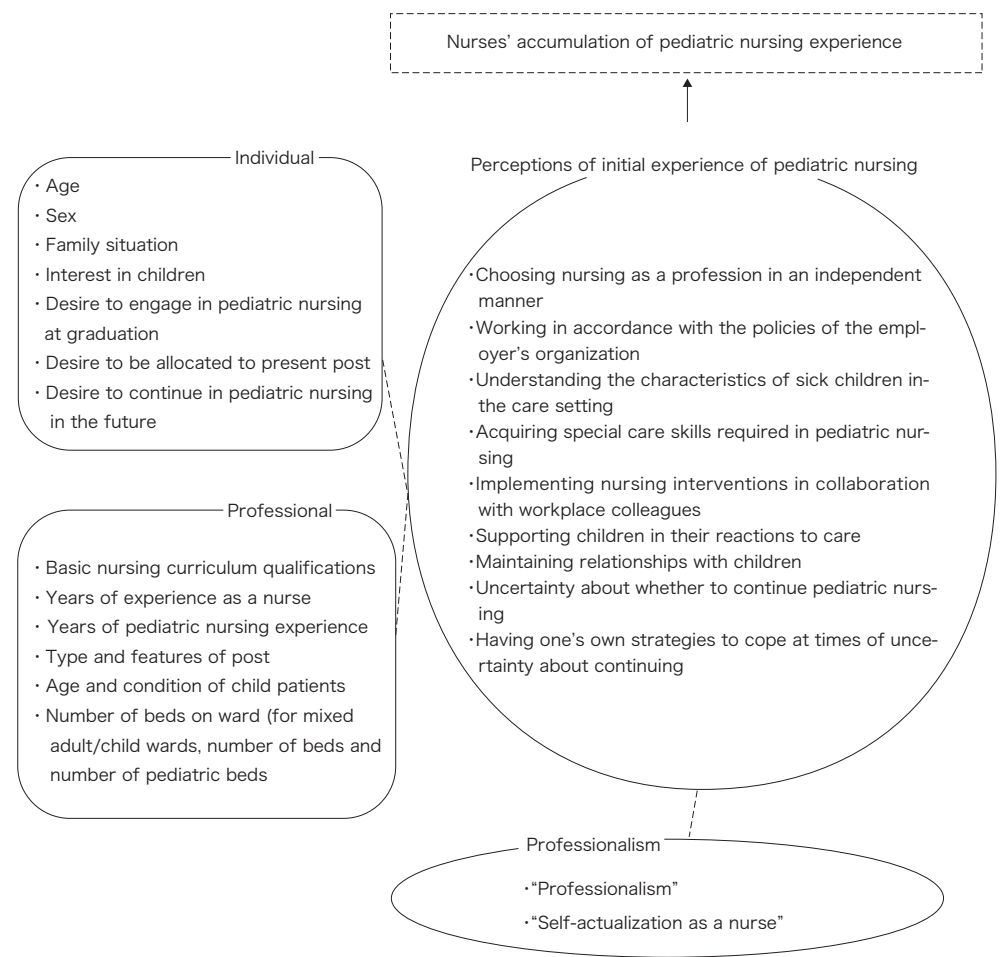

Fig. 1 Research framework

elicited from qualitative inductive analysis of interviews conducted with 12 nurses who had 2-5 years' pediatric nursing experience. Specific question content concerned : (1) choosing nursing as a profession in an independent manner ; (2) working in accordance with the policies of the employer's organization ; (3) understanding the characteristics of sick children in the care setting ; (4) acquiring special care skills required in pediatric nursing; (5) implementing nursing interventions in collaboration with workplace colleagues ; (6) supporting children in their reactions to care ; (7) maintaining relationships with children ; (8) uncertainty about whether to continue pediatric nursing ; and (9) having one's own strategies to cope at times of uncertainty about continuing. Each item was rated "strongly agree" (5 points), "agree somewhat" (4 points), "agree slightly” (3 points), “disagree slightly" (2 points), or "completely disagree" (1 point).

3) Self-actualization as a nurse and professionalism

For this measurement, we used the Nurses' Job Satisfaction and Value Allocation scale (Nakayama and Nojima, 2001), which has been verified in terms of validity and reliability. This scale consists of four sub-scales measuring "management systems" (15 items), "human relations at work" (26 items), "professionalism" (12 items), and"self-actualization as a nurse" (10 items). Each sub-scale can be used independently, (Nakayama and Nojima, 2001), and the present study used the "professionalism" and "self-actualization as a nurse" subscales. On these sub-scales, options for responses for the 17 affirmative content items on a 5 -point scale were "strongly agree" (5 points), "agree some- 
what” (4 points), "agree slightly" (3 points), "disagree slightly" (2 points), and "completely disagree" ( 1 point), while responses for the 5 negative items (5 items in "professionalism") were scored "strongly agree" (1 point), "agree somewhat" (2 points), "agree slightly" (3 points), "disagree slightly" (4 points), or "completely disagree” (5 points). Permission to use the scale was obtained from its developers.

\section{Analysis}

Analyses involving descriptive statistical calculations, correlation coefficient calculations and tests, factor analysis, and t-tests were conducted using SPSS. v. 16.0J for Windows.

\section{Ethical considerations}

An explanation of the research aims and methods was included in the letter requesting cooperation that was distributed to heads of nursing at participating institutions and to participants. This explanation included the following points. A summary of results was sent to hospitals, and the research was disseminated through journal articles and conference presentations. Data analysis was carried out for the group as a whole, with no analysis of individuals' data. Returned envelopes were shredded immediately after being opened, data stored on computers were deleted at the end of the study, and questionnaire forms were shredded. Questionnaires were anonymous, collected by means of individual return by post, and individuals were not identified by any means. The name and contact details of the researchers were clearly provided. Return of the questionnaire was taken as consent to participate in the study. When the request to distribute the questionnaire was made to the hospital nursing department, those responsible for distributing the questionnaire were also asked to inform participants that participation in the study was voluntary, and they were asked only to distribute the questionnaire and request for cooperation, and not to follow up on collection.

\section{Results}

Replies were obtained from 299 respondents (response rate $65.1 \%$ ). The responses of 73 nurses were excluded; these were from 60 nurses with less than 2 years' pediatric nursing experience, 6 who had left many questions blank, and 7 who did not choose any option for the question regarding whether they wanted to further their experience in pediatric nursing or who wrote answers other than the available options. A total of 226 responses (valid response rate $75.5 \%$ ) remained for analysis.

\section{Participants' characteristics}

As can be seen in Table 1, which shows individual characteristics, the vast majority of respondents were women, and their mean age was 35.8 years (SD, 8.6). Most of them were living with family, with $73.4 \%$ living in either nuclear or extended families, and a majority of $88.9 \%$ reported an interest in children.

In terms of professional factors, the highest nursing qualification, held by a majority of $84.1 \%$, was vocational school graduation. Mean nursing experience was 12.8 years $(\mathrm{SD}, 8.4)$, and $60.6 \%$ had $3-6$ years' experience of pediatric nursing, with the mean being 6.4 years (SD, 5.2). Most respondents were employed on wards, with $44.2 \%$ on childonly wards and $55.8 \%$ on mixed child/adult wards. The mean number of beds on the wards they were employed on was 35 (range, 6-79; SD, 12.8). More than half of the places of employment dealt with acute pediatric conditions, and the most common age range of patients, at $36.7 \%$, was all ages treated in pediatric departments, namely, neonates, infants, children, and over-15s. 
Table 1 Attributes of participants $(\mathrm{N}=226)$

\begin{tabular}{|c|c|c|c|c|}
\hline & Item & Category & Number & $\%$ \\
\hline \multirow{17}{*}{$\begin{array}{l}\text { Individual } \\
\text { factors }\end{array}$} & \multirow[t]{2}{*}{ Sex } & Male & 7 & 3.1 \\
\hline & & Female & 219 & 96.9 \\
\hline & \multirow[t]{4}{*}{ Age } & $22-29$ years old & 56 & 24.8 \\
\hline & & 30-39 years old & 104 & 46.1 \\
\hline & & 40-49 years old & 46 & 20.3 \\
\hline & & $50-58$ years old & 20 & 8.8 \\
\hline & \multirow[t]{3}{*}{ Family situation } & Living alone & 60 & 26.5 \\
\hline & & Nuclear family & 139 & 61.5 \\
\hline & & Extended family & 27 & 11.9 \\
\hline & \multirow[t]{2}{*}{ Interest in children } & Yes & 201 & 88.9 \\
\hline & & No & 25 & 11.1 \\
\hline & \multirow{2}{*}{$\begin{array}{l}\text { Desire to work in pediatric nursing } \\
\text { at time of graduation }\end{array}$} & Yes & 98 & 43.4 \\
\hline & & No & 128 & 56.6 \\
\hline & \multirow[t]{2}{*}{ Desire to be allocated to present post } & Yes & 85 & 37.6 \\
\hline & & No & 141 & 62.4 \\
\hline & \multirow{2}{*}{$\begin{array}{l}\text { Desire to gain further experience in } \\
\text { pediatric nursing in the future }\end{array}$} & Yes & 171 & 75.7 \\
\hline & & No & 55 & 24.3 \\
\hline \multirow{10}{*}{$\begin{array}{l}\text { Professional } \\
\text { factors }\end{array}$} & \multirow[t]{4}{*}{ Basic nursing qualifications } & Vocational school & 190 & 84.1 \\
\hline & & Junior college & 23 & 10.2 \\
\hline & & $\begin{array}{l}\text { University/graduate } \\
\text { school }\end{array}$ & 9 & 3.9 \\
\hline & & Other & 4 & 1.8 \\
\hline & \multirow[t]{2}{*}{ Pediatric nursing experience } & $2-5$ years & 137 & 60.6 \\
\hline & & 6 or more years & 89 & 39.4 \\
\hline & \multirow[t]{2}{*}{ Place of employment } & Outpatients & 17 & 7.5 \\
\hline & & Ward & 209 & 92.5 \\
\hline & \multirow[t]{2}{*}{ Features of place of employment } & Children only & 100 & 44.2 \\
\hline & & $\begin{array}{l}\text { Mixed } \\
\text { children/adult }\end{array}$ & 126 & 55.8 \\
\hline
\end{tabular}

At the time of graduation, $43.4 \%$ of respondents wanted to be employed in pediatric nursing, while $56.6 \%$ did not have such a desire. At the time of the questionnaire, $75.7 \%$ stated that they would like to further their experience in pediatric nursing in the future.

\section{Construction of perceptions of initial experience of pediatric nursing practice}

In order to identify the construction of registered nurses' perceptions of initial experience of pediatric nursing practice, factor analysis was con- ducted using promax rotation and maximum likelihood estimation. This was performed after excluding one item (choosing nursing as a profession according to one's own will) that had low communality with the rest of the nine items related to perceptions of nurses with 2-5 years' experience. With a standard of 0.4 factor loading and factor scree plot, analysis results elicited two factors and eight items. The first factor consisted of the five items of "acquiring skills of special care required in pediatric nursing", "understanding the characteristics of sick children in the care setting", "uncer- 
Table 2 Factor analysis of nurses' perceptions of initial experience of pediatric nursing practice (maximum likelihood estimation, promax rotation) $(\mathrm{N}=226)$

\begin{tabular}{|c|c|c|c|}
\hline \multirow[t]{2}{*}{ Factor name and items } & \multicolumn{2}{|c|}{ Factor loading } & \multirow[t]{2}{*}{ Communality } \\
\hline & First factor & Second factor & \\
\hline \multicolumn{4}{|l|}{ "Professional development as a pediatric nurse" factor $\alpha=0.733$} \\
\hline $\begin{array}{l}\text { Understanding the characteristics of sick children in the care set- } \\
\text { ting }\end{array}$ & 0.687 & 0.155 & 0.627 \\
\hline Acquiring special care skills required in pediatric nursing & 0.702 & 0.102 & 0.592 \\
\hline Uncertainty about whether to continue pediatric nursing & -0.585 & 0.302 & 0.217 \\
\hline Supporting children in their reactions to care & 0.580 & -0.070 & 0.291 \\
\hline Maintaining relationships with children & 0.528 & 0.181 & 0.428 \\
\hline \multicolumn{4}{|l|}{ "Capacity to work" factor $\quad \alpha=0.597$} \\
\hline $\begin{array}{l}\text { Having one's own strategies to cope at times of uncertainty } \\
\text { about continuing }\end{array}$ & -0.215 & 0.679 & 0.328 \\
\hline $\begin{array}{l}\text { Implementing nursing interventions in collaboration with work- } \\
\text { place colleagues }\end{array}$ & 0.059 & 0.590 & 0.394 \\
\hline $\begin{array}{l}\text { Working in accordance with the policies of the employer's organi- } \\
\text { zation }\end{array}$ & -0.025 & 0.566 & 0.303 \\
\hline Eigenvalue & 3.120 & 1.317 & \\
\hline Contribution $(\%)$ & 31.985 & 7.771 & \\
\hline Cumulative contribution (\%) & & 39.757 & \\
\hline \multicolumn{4}{|l|}{ Reliability coefficient of all items $\alpha=0.740$} \\
\hline \multirow[t]{2}{*}{ Factor correlation } & 1 & 0.354 & \\
\hline & 0.354 & 1 & \\
\hline
\end{tabular}

tainty about whether to continue pediatric nursing”, "supporting children in their reactions to care", and "maintaining relationships with children". Because the content of these items was related to professional development as a pediatric nurse through experience of pediatric nursing, this factor was labeled "professional development as a pediatric nurse". The second factor consisted of the three items of "having one's own strategies to cope at times of uncertainty about continuing", "implementing nursing interventions in collaboration with workplace colleagues", and "working in accordance with the policies of the employer's organization". Since these factors were connected with individual and team capacity necessary for the nurse to accomplish work, and with the capacity of the organization, this factor was labeled "capacity to work” (Table 2).
The reliability of the two factors and all items structuring perceptions of initial experience of pediatric nursing was tested using Cronbach's alpha coefficient. The alpha coefficient was 0.733 for the factor, "professional development as a pediatric nurse”, 0.597 for the factor "capacity to work", and 0.740 for all items. This shows that the items in "professional development as a pediatric nurse" have communality in showing the factors affecting nurses' development as pediatric nurses from the initial stage of pediatric nursing practice. On the other hand, the reliability coefficient for the "capacity to work" factor was low, showing that there was little communality among the three items comprising this factor.

Furthermore, the construct validity of the factor analysis was confirmed through a Kaiser-MeyerOlkin measure of sampling adequacy of 0.765 for 
this model. Confirmation that the content of items included in the two factors did reflect concepts related to retention in pediatric nursing was obtained through four nursing professionals with at least 3 years of pediatric nursing experience. Moreover, internal validity was confirmed through examination of whether the factor names were valid, conducted by two researchers and a nursing management professional who collectively had 37 years' nursing experience, including 4 years' experience of pediatric nursing.

Correlations between the two factors structuring perceptions of initial experience of pediatric nursing practice and the "professionalism" and "selfactualization as a nurse" sub-scales of the Nurses' Job Satisfaction and Value Allocation scale were also analyzed. In terms of correlation coefficients, attention was paid to significance levels and their values, and correlations were defined as relationships with $r$ values greater than 0.3. Results showed a high correlation between the "professional development as a pediatric nurse” factor and both "professionalism” ( $\mathrm{r}=0.563, \mathrm{p}<0.01)$ and "selfactualization as a nurse" $(r=0.560, \mathrm{p}<0.01)$. In addition, a weak correlation was evident between the "capacity to work" factor and both "professionalism" ( $\mathrm{r}=0.339, \mathrm{p}<0.01)$ and "self-actualization as a nurse" $(r=0.403, p<0.01)$, enabling us to confirm criterion validity. It is thus clear than nurses' perceptions of initial experience of pediatric nursing practice are formed from the two factors of "professional development as a pediatric nurse" and “capacity to work".

3. Differences in construction of perceptions of initial experience of pediatric nursing practice according to nurses' years of experience of pediatric nursing and attributional factors

In scores on the two factors structuring nurses' perceptions of initial experience of pediatric nursing practice, factor loading for "uncertainty about whether to continue pediatric nursing" proved to be negative, so scores were reversed in calculations, giving a mean of 17.38 (range, 5.0-25.0 ; SD, 3.19) for "professional development as a pediatric nurse" and a mean of 10.68 (range 6.0-15.0 ; SD, 1.78) for "capacity to work". In terms of the two factors structuring nurses' perceptions of initial experience of pediatric nursing practice, a $\mathrm{t}$-test was conducted in order to show differences according to nurses' attributes.

The group with more than 6 years' experience of pediatric nursing had significantly higher mean scores on the "professional development as a pediatric nurse" factor than the group with 2-5 years' experience.

As far as other attributes were concerned, the group of nurses that expressed an interest in children had a higher mean score on the "professional development as a nurse" factor than the group that did not have this interest as an individual factor. Similarly, those that had expressed a desire to be allocated to their present post had higher mean scores on the "professional development as a nurse" factor than those who had not; those who had wanted to be employed in pediatric nursing at the time of graduation had higher mean scores on the "professional development as a nurse" factor than those who had not; and those who expressed a desire at the time of the questionnaire to continue furthering their experience in pediatric nursing in the future had significantly higher mean scores on both the "professional development as a nurse" factor and the "capacity to work" factors than those without this desire. In terms of work factors, those working in outpatient settings had higher mean scores on "professional development as a nurse" than those working on wards, and those working in settings where they only dealt with chil- 
Table 3 Links between factors structuring nurses' perceptions of initial experience of pediatric nursing practice and attributional factors: Comparison of mean differences according to differences in nurses'attributes $(\mathrm{N}=226)$

\begin{tabular}{|c|c|c|c|c|c|c|c|c|}
\hline \multirow[t]{2}{*}{ Attributional factor } & & \multirow[b]{2}{*}{$\mathrm{n}$} & \multicolumn{3}{|c|}{$\begin{array}{c}\text { Professional development as } \\
\text { a pediatric nurse }\end{array}$} & \multicolumn{3}{|c|}{ Capacity to work } \\
\hline & & & M (SD) & $t$ & $p$ & M (SD) & $t$ & $p$ \\
\hline \multirow[t]{2}{*}{ Interest in children } & Yes & 201 & $17.86(2.93)$ & 7.07 & $* * *$ & 一 & - & $n s$ \\
\hline & No & 25 & $13.52(2.51)$ & & & - & & \\
\hline \multirow{2}{*}{$\begin{array}{l}\text { Desire to be allocated to } \\
\text { present post }\end{array}$} & Yes & 85 & $18.34(3.06)$ & 3.60 & $* * *$ & - & - & $n s$ \\
\hline & No & 141 & $16.80(3.13)$ & & & - & & \\
\hline \multirow{2}{*}{$\begin{array}{l}\text { Desire to be employed in } \\
\text { pediatric nursing at time of } \\
\text { graduation }\end{array}$} & Yes & 98 & $18.59(2.86)$ & 5.27 & $* * *$ & - & - & $n s$ \\
\hline & No & 128 & $16.45(3.13)$ & & & - & & \\
\hline \multirow{2}{*}{$\begin{array}{l}\text { Desire to gain further expe- } \\
\text { rience in pediatric nursing } \\
\text { in future }\end{array}$} & Yes & 171 & $18.34(2.75)$ & 9.44 & $* * *$ & $10.81(1.72)$ & 1.99 & $*$ \\
\hline & No & 55 & $14.38(2.56)$ & & & $10.27(1.91)$ & & \\
\hline \multirow[t]{2}{*}{ Pediatric nursing experience } & 6 or more yrs & 89 & $18.91(3.00)$ & 6.27 & $* * *$ & - & - & $n s$ \\
\hline & $2-5 \mathrm{yrs}$ & 137 & $16.38(2.91)$ & & & - & & \\
\hline \multirow[t]{2}{*}{ Type of workplace } & Outpatients & 17 & $19.47(3.00)$ & 2.85 & $* *$ & - & - & $n s$ \\
\hline & Ward & 209 & $17.21(3.15)$ & & & - & & \\
\hline \multirow[t]{2}{*}{ Features of workplace } & Children only & 100 & $18.41(2.84)$ & 4.49 & $* * *$ & $11.02(1.69)$ & 2.55 & $*$ \\
\hline & $\begin{array}{l}\text { Mixed } \\
\text { children/adult }\end{array}$ & 126 & $16.56(3.23)$ & & & $10.42(1.81)$ & & \\
\hline
\end{tabular}

dren had higher mean scores on both the "professional development as a nurse" and "capacity to work" factors than those working in mixed adult/ child settings (Table 3 ).

\section{Discussion}

\section{Construction of nurses' perceptions of initial experience of pediatric nursing practice}

The eight items of nurses' perceptions of initial experience of pediatric nursing practice were divided through factor analysis into two factors, "professional development as a pediatric nurse" and “capacity to work".

The factor "professional development as a pediatric nurse" signifies development through experience of understanding the characteristics of sick children, acquiring skills of specialized care, maintaining relationships with children, and also think- ing about abandoning pediatric nursing. Saito et al. (1996) specified four factors characteristic of pediatric nurses, one of which is facilitating the child's development, which overlaps with the acquisition of skills of specialized pediatric nursing care identified in the present study. Nishida (2003) identified the expertise of pediatric nurses as residing in their cultivation of the autonomy of children, with this including support for the family, support for growth and development, and support for motivation to fight illness. Support for the families of child patients and for the growth and development of children are matched by the pediatric nursing specialist care shown in the results of this study.

Because items connected to the professionalism of pediatric nursing are included in the "professional development as a pediatric nurse" factor, it can be assumed that registered nurses begin to acquire the expertise of pediatric nursing from the 
initial stage of pediatric nursing practice. According to Smart and Kotzer (2003), one effective strategy in the employment of pediatric nurses is for students and nurses aiming to become pediatric nurses to gain an understanding of the professionalism of pediatric nurses through nursing experience in a children's hospital. This study showed that acquisition of pediatric nursing professionalism was a factor involved in development as a pediatric nurse, agreeing with previous studies regarding the importance of the acquisition of professionalism as a pediatric nurse.

The "capacity to work” factor indicated nurses' ability to adapt to the workplace and engage in the work of pediatric nursing through experience, including having their own strategies to deal with facing times of uncertainty about continuing pediatric nursing, implementing nursing interventions in collaboration with workplace colleagues, and working in accordance with the policies of the employer's organization.

On the issue of the nursing professional identity of registered nurses with 2 years' experience, Fargerberg and Kihlgren (2001) highlighted the role of the nurse in relation to patient care and individual responsibility and understanding within the organization. This study found that the "capacity to work" recognized by nurses has commonality with individual responsibility within the organization as an aspect of identity as a nursing professional. It would seem to be important for registered nurses to execute their own role in the organization in order to provide nursing care. Furthermore, "capacity to work" indicates the ability to adapt to the working environment, and thereby to continue working as a pediatric nurse.

It has been pointed out that the main factors related to nurse retention are management and administration of the workplace organization, together with human relations in the workplace
(Cangelosi et al., 1998 ; Persons and Stonestreet, 2004). These factors are at one with the content indicated in pediatric nurses' "capacity to work".

This being the case, it is necessary to create a workplace in which individuals find it easy to work as a way of enabling nurses to adapt to the workplace and fully engage in their roles as pediatric nurses. It can be assumed that individual nurses engaging in interpersonal communication aimed at maintaining good human relations with colleagues and other professionals, and also consciously aiming to create a setting where it is easy to work, will strengthen their "capacity to work".

\section{Differences in factors structuring percep-} tions of initial experience of pediatric nursing practice according to nurses' attributes

The six factors influencing "professional development as a pediatric nurse" were having an interest in children, having the desire to be employed in pediatric nursing at the point of graduation, having requested to be allocated to the present post, having more than 6 years' experience of pediatric nursing, working in an outpatient setting, and working in a setting where all patients are children. The individual factors of nurses influencing their "professional development as a pediatric nurse" are their interest in children and desire to be allocated to their present post based on a desire to acquire experience in pediatric nursing from the point of graduation, and these factors all indicate the nurses' positive desire for engagement in work involving children. As Smart and Kotzer (2003) have shown, providing practical pediatric nursing experience to high school students, pre-employment nurses, and nursing students is an effective employment strategy at a children's hospital. The reason for this, as well as students and nurses acquiring an understanding of the professionalism 
of pediatric nursing, is the approach to the individual factor of interest in children indicated in this study. It seems that experience of the actual work of pediatric nurses leads to understanding of the characteristics of care of child patients, while involvement with children facilitates interest, encouraging nurses to aim to specialize in pediatrics. In this context, it is important for nurses who have a desire to further their experience in pediatric nursing to be allocated to a post in which they can engage in this type of nursing, and post allocation needs to take into account the nurse's own wishes in this regard. Furthermore, nurses who have more than 6 years' experience of pediatric nursing retain the "professional development as a pediatric nurse" experienced through 2-5 years employment in pediatric nursing, and the fact that their mean scores are higher than those of nurses with 2-5 years' experience indicates that they have a stronger perception of professional development as a pediatric nurse gained through amassed experience in this specialty. Hence, attention should be paid to making sure that pediatric nurses can further their experience in pediatric nursing, because this will contribute to the development of expert nurses in the field.

According to Donner and Wheeler (2001), registered nurses' growth as professionals consists of five stages. Registered nurses with more than 6 years' experience are at the stage of consolidation as a professional. It can be argued that the reason these nurses are so strongly aware of their development as pediatric nurses is that they are in the period of consolidating their skills and knowledge as nursing professionals. That is, registered nurses with more than 6 years' experience consolidate their specialist knowledge and skills through the accumulation of experience of pediatric nursing, and they implement highly specialized care. In this respect, it is important to support pediatric nurses, enabling them to build up their experience of pediatric nursing practice, in order for them to provide high-quality nursing to patients. Furthermore, the fact that mean scores for "professional development as a pediatric nurse" were higher for pediatric nurses working in outpatient settings or in settings where they deal only with children may indicate that nurses working in these settings have a high level of awareness of practice in terms of understanding the characteristics of sick children, acquiring competence in specialist care, and engaging in nursing for children and their families while maintaining relationships with children. Taking into account the fact that pediatric outpatient work frequently involves direct care related to examinations and treatment, involving help in making the child feel secure and comfortable and providing psychological support (Hirabayashi et al., 1999), pediatric outpatient nurses are constantly involved in observing the condition of children and in trying to ensure their security and comfort depending on their age and condition. This means that they are constantly practicing awareness of the items that constitute "professional development as a pediatric nurse".

In pediatric outpatients and work environments where all patients are children, play areas or other facilities for children are often provided, making the environment more child-friendly. This kind of child-friendly environment makes it easier for nurses to adapt their care to children's lives. If the environment is organized to meet the needs of sick children, nurses are able to provide nursing that makes the most of that environment with full awareness that they are engaged in pediatric nursing, and this may heighten their consciousness of "professional development as a pediatric nurse", explaining their high mean scores. In recent years, there has been a tendency to downsize pediatric outpatient departments, pediatric department 
wards, and pediatric wards in hospitals, but it is important for children and their families to be able to receive treatment and nursing in an environment adapted to the needs of sick children, and it is simultaneously important for nurses to have this environment in which to practice pediatric nursing. Even in cases where children are on mixed wards with adult patients, it is necessary to have rooms just for children, and to ensure that nursing management takes into account the lifestyle needs of children.

The two main factors influencing "capacity to work" were the desire to gain further experience of pediatric nursing in the future and working in a child-only environment in the allocated post. "Capacity to work" means that nurses have the ability to acclimatize to the workplace organization in order to effectively engage in the practice of pediatric nursing. It seems likely that if nurses are working in their present post with the desire to acquire further experience in pediatric nursing in the future, this will be connected to their wish to continue in their present work, and will heighten their "capacity to work". It can also be supposed that, in environments where nurses are involved only with child patients, the fact that their nursing is limited to children means that they can concentrate on the work of pediatric nursing. The implications here are that the organization of an environment that enables nurses to maintain their own positive motivation to engage in pediatric nursing as they work is important if pediatric nurses are to develop the "capacity to work". This shows that nurses are shaping their workplace organizations in order to do their work.

Bratt et al. (2000) identify job stress and nursing leadership behaviors as the two variables influencing job satisfaction among pediatric intensive care unit nurses. Nursing leadership behaviors are management behaviors that enable staff to accomplish their work in meaningful ways (Bratt et al., 2000), and this indicates that it is important for pediatric nurses to have autonomy in their professional duties to manage their own work. The results of this study show that nurses who worked in units comprising only child patients were, like the pediatric intensive care unit nurses, involved only in pediatric nursing. It appears that increased capacity to work among such nurses involves being able to concentrate on work that is well-defined within a specialist field, where management skills are improved and they have autonomy in the workplace system.

Additionally, increased "capacity to work" caused by the desire of nurses to continue building experience in pediatric nursing indicates the importance of shaping workplace systems for job retention among pediatric nurses. Smart and Kotzer (2003) state that one strategy for retention of nurses in children's hospitals is for nursing management departments to make time to listen to the opinions of the nurses. The time to listen strategy involves nursing management departments listening to the opinions of the nurses they employ regarding their work, and providing a place for discussion (Smart and Kotzer, 2003). For pediatric nurses, having opportunities to be able to express their opinions about work means that they are engaged in the workplace with their own opinions. In other words, it is important for pediatric nurses to have a voice in shaping their own workplace systems if they are to be retained. Similarly, the results of this study show that positive engagement in adapting to the workplace and shaping workplace systems is linked to the desire among nurses to build up experience in the work of pediatric nursing or to retention.

\section{Limitations of the study and future issues}

This study clarified the structure of perceptions 
of the initial experience of pediatric nursing among registered nurses with more than 2 years' experience, together with differences in attributes. However, it does not address the issue of how newly graduated nurses and nurses with less than 2 years' experience reflect on their experiences of pediatric nursing and perceive their practice. Further research with such nurses is necessary in order to discover how they perceive their experience.

It is also unclear what kind of understanding registered nurses with many years of experience have, apart from the perceptions of their initial experience. There would seem to be other factors required for pediatric nurse retention, and there is accordingly a need to clarify the perceptions of registered nurses with more than 6 years' experience in greater detail. In addition, because content communality was low for the items comprising "capacity to work", the question of whether further question content is necessary concerning the kinds of experiences involved in this factor should be investigated. Further, in order to clarify important experiences that encourage retention of nurses in pediatric nursing, it is important to clarify what kinds of perceptions nurses develop, apart from "professional development as a pediatric nurse" and "capacity to work", through continuing pediatric nursing beyond the initial stage of experience.

\section{Conclusions}

Through the use of a questionnaire administered to nurses with more than 2 years' experience of pediatric nursing practice, this study revealed that nurses' perceptions of their initial experience of pediatric nursing practice comprise the two factors of "professional development as a pediatric nurse" and "capacity to work". As far as differences in the two factors in terms of nurses' attributes were concerned, nurses who had an interest in children, had more than 6 years' experience of pediatric nursing, worked in an outpatient setting, worked in a setting where all patients are children, had the desire to be employed in pediatric nursing at the point of graduation and time of allocation to the present post, and expressed a desire to continue developing their experience in pediatric nursing had high mean scores on "professional development as a pediatric nurse". Nurses who worked in environments where they were dealing only with child patients, and those who, at the time of the study, expressed a desire to continue extending their experience in pediatric nursing in the future, recorded high mean scores on "capacity to work". It seems that the more experience nurses accumulated with pediatric nursing, the more they were conscious of "professional development as a pediatric nurse", and that positive engagement in shaping workplace systems to accumulate work experience raised "capacity to work" among pediatric nurses.

This suggests that it is not only practical competence in the provision of specialist care that is necessary for nurses with 2-5 years' experience of pediatric nursing to extend their experience of nursing in this field, but that there is also a need to provide opportunities for nurses to reflect on the nursing practice on a daily basis, and to ensure an environment conducive to the practice of pediatric nursing.

\section{Acknowledgements}

We would like to express sincere thanks to all nursing departments that collaborated and the pediatric nurses who participated in this study.

\section{References}

Bratt MM, Broome M and Kelber S (2000) Influence of stress and nursing leadership on job satisfaction of pediatric intensive care unit nurses. Am J Crit Care, 


\section{9, 307-317}

Cangelosi JD, Markham FS and Bounds WT (1998) Factors related to nurse retention and turnover: an updated study, Health Mark Q, 15, 25-43

Donner GJ and Wheeler MM (2001) Career planning and development for nurses : the time has come, Int Nurs Rev, 48, 79-85

Fagerberg I and Kihalgren M (2001) Experiencing a nurse identity : the meaning of identity to Swedish registered nurses 2 years after graduation, J Adv Nurs, 34, 137-145

Hirabayashi Y, Oikawa I, Suzuki C, et al. (1999) Duties of pediatric outpatient nurses and duties perceived as “nursing roles” by nurses, St Luke's College of Nursing University Bulletin, 25, 41-51 (in Japanese)

Levinson DJ (1978) The Seasons of a Man's Life, Ballantine (New York)

Ministry of Health (2003) Hospitals Directory, Igakushoin (Tokyo) (in Japanese)

Nakayama Y and Nojima S (2001) Analysis of factors concerning nurses' retention and job satisfaction, Kango, 53 (8), 81-91 (in Japanese)

Nishida M(2003) Specific Features of pediatric nursing : research on nurses practicing pediatric nursing, Jour- nal of Japanese Society of Child Health Nursing, 12 (2), 53-58 (in Japanese)

Ode M (2007) Nursing management requested from pediatric nursing : operation of nursing service in ward and outpatient, The Japanese Journal of Child Nursing, 30, 1108-1113 (in Japanese)

Persons ML and Stonestreet J (2004) Staff nurse retention : laying the groundwork by listening, Nurs Leadersh Forum, 8, 107-113

Saito Y, Hamanaka K and Saito Y (1996) A study on the factors of development for specific features of pediatric nurses, Proceedings of the Japan Nursing Association, 27, 96-99 (in Japanese)

Smart G and Kotzer AM (2003) STAT! A four-step approach to nursing recruitment and retention in a tertiary pediatric setting, Nurs Leadersh Forum, 8, $72-77$

Taniguchi M, Terae K, Takada H, et al. (2001) A study on examination of rotation in registered nurses' career development, Japanese Nursing Association Collected Papers, Nursing Management, 32, 393-395 (in Japanese)

(Received 10. 7. 2010 ; Accepted 8. 29. 2011) 